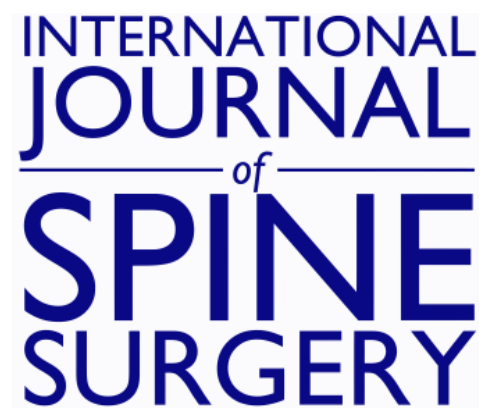

\title{
Transforaminal Endoscopic Lumbar Discectomy: Basic Concepts and Technical Keys to Clinical Success
}

Sang Gu Lee and Yong Ahn

Int J Spine Surg 2021, 15 (suppl 3) S38-S46

doi: https://doi.org/10.14444/8162

http://ijssurgery.com/content/15/suppl_3/S38

This information is current as of April 25, 2023.

Email Alerts Receive free email-alerts when new articles cite this article. Sign up at:

http://ijssurgery.com/alerts

The International Journal of Spine Surgery

2397 Waterbury Circle, Suite 1,

Aurora, IL 60504, Phone: +1-630-375-1432 


\title{
Transforaminal Endoscopic Lumbar Discectomy: Basic Concepts and Technical Keys to Clinical Success
}

\author{
SANG GU LEE, MD, PHD ${ }^{1}$ AND YONG AHN, MD, PHD ${ }^{1}$ \\ ${ }^{I}$ Department of Neurosurgery, Gil Medical Center, Gachon University College of Medicine, Incheon, South Korea
}

\begin{abstract}
Background: Open microdiscectomy is the gold standard surgical technique for radiculopathy with lumbar disc herniation (LDH). Transforaminal endoscopic lumbar discectomy (TELD) has been developed as an effective and minimally invasive alternative to open surgery. As a result of these remarkable technical evolutions, the clinical outcomes of TELD have become comparable to those of conventional open surgery. However, considerable learning curves and endoscopy-related adverse events may emerge as critical problems.

Objective: The objective of this article was to inform on the basic principles, surgical techniques, and keys to clinical success in preventing complications.

Methods: A narrative review of the literature focused on the surgical indications, technical tips, complications, and learning curve of the full-endoscopic procedure was performed.

Results: First, the transforaminal endoscopic system should access as close as possible to the target point, avoiding exiting nerve root irritation. Second, selective removal of the herniated disc fragments after sufficiently releasing the annular anchorage parts is essential to avoid incomplete decompression or prevent an early recurrence. Third, the endpoint of the procedure can be determined at the point of solid pulsation and free mobilization of the nerve root. Finally, surgeons should always ensure that the anatomical layers discriminate the neural tissue and disc material during the procedure.

Some authors have demonstrated the effectiveness of TELD through randomized controlled trials, meta-analyses, and systemic reviews. According to these studies, the clinical outcomes of TELD are not inferior to those of open discectomy, with an earlier recovery period and fewer complications.

Conclusions: The full-endoscopic transforaminal discectomy technique for soft LDH is an effective alternative with the benefits of minimally invasive surgery in appropriately selected patients. Given recent technical developments, the surgical indications for TELD will be broader and the clinical outcomes will be more reliable.
\end{abstract}

Special Issue

Keywords: complication, discectomy, endoscopic, lumbar disc, percutaneous, transforaminal

\section{INTRODUCTION}

The standard surgical technique for lumbar radiculopathy caused by lumbar disc herniation (LDH) is open microdiscectomy. ${ }^{1-6} \mathrm{~A}$ spine surgeon can safely remove the herniated disc under precise surgical microscopic visualization. The surgical outcome is excellent and relevantly better when compared with open radical discectomy. However, there might be some adverse effects of muscle retraction, wide laminectomy with facetectomy, and excessive manipulation of the dural sac.

Almost 50 years ago, pioneers of minimally invasive spine surgery developed a posterolateral percutaneous discectomy technique for some LDH cases, ${ }^{7,8}$ aiming to percutaneously decompress the compressed nerve root while minimizing normal tissue trauma. Posterolateral lumbar discectomy and decompression are performed through the foraminal opening, bypassing the posterior normal tissues. This concept has evolved into modern transforaminal endoscopic lumbar discectomy (TELD). ${ }^{9,10}$

There is an increasing trend for using endoscopic spine surgery in the spine society, driven by the current relevance given to postsurgical quality of life and recovery time. ${ }^{11,12}$

This review article discusses the characteristics of the TELD technique and describes the indications and technical tips to achieve reliable clinical success while preventing unexpected surgical complications. These guidelines will help spine surgeons learn about endoscopic spine surgery and apply it in actual practice.

\section{BASIC CONCEPTS}

\section{Terminology}

There are different types of endoscopic spine surgery based on the properties of endoscopes: full-endoscopic (or percutaneous endoscopic), microendoscopic, 


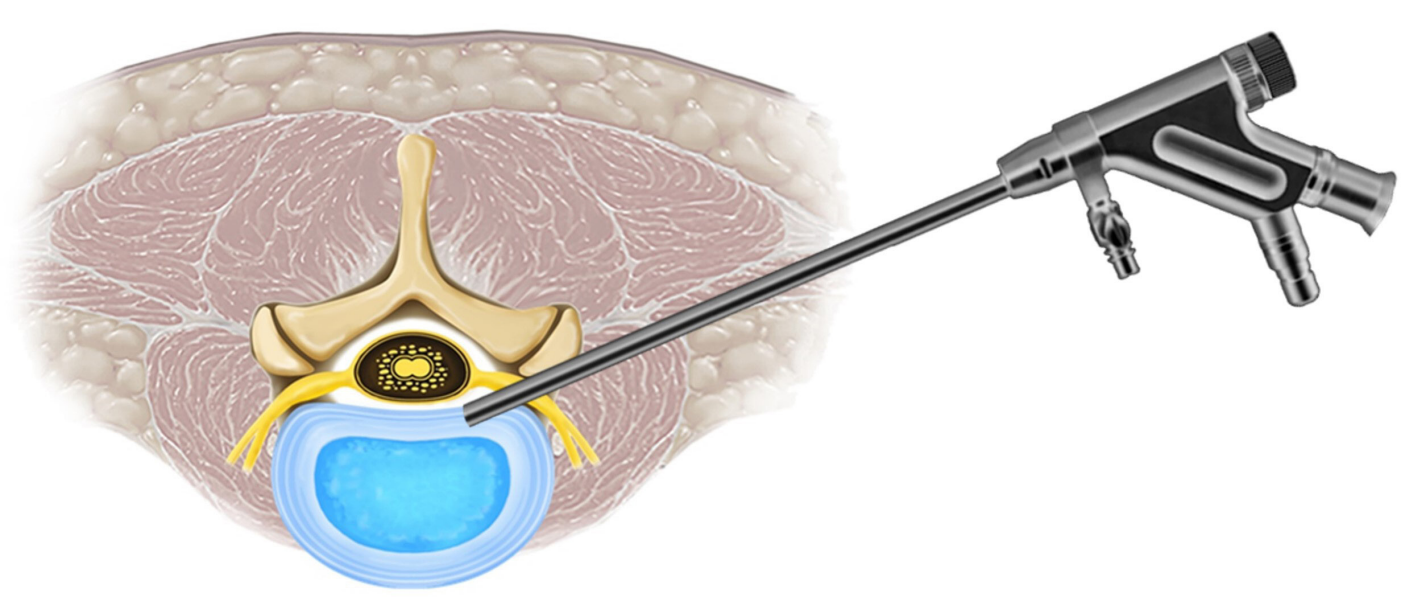

Figure 1. Basic principle of transforaminal endoscopic lumbar discectomy. The percutaneous endoscopic approach provides direct access to the pathologic disc through the foraminal window, bypassing the posterior healthy structures.

biportal endoscopic, and epiduroscopic. ${ }^{13-16}$ Fullendoscopic or percutaneous endoscopic lumbar discectomy is the most commonly used endoscopic surgery. This technique has the following common characteristics: (1) application of a working channel endoscope that includes an optic system and a working channel in a thin tubular device; (2) a complete percutaneous introduction with a stab incision; and (3) a monoportal procedure performed under constant saline irrigation. ${ }^{15}$ Regarding the lumbar spine, there are two approaches to full-endoscopic discectomy: transforaminal and interlaminar. Transforaminal full-endoscopic lumbar discectomy has been developed as a representative endoscopic spine surgery. Although the terminology used to describe this technique is varied, the AOSpine group proposed the unified term "transforaminal endoscopic lumbar discectomy" (TELD). ${ }^{17}$

\section{Bypass Surgery: The Transforaminal Approach}

The main aspect of TELD is being a "bypass surgery." This implies a direct approach to the pathologic disc through a safe foraminal window (Figure 1). Open lumbar discectomy or microdiscectomy requires a linear skin incision, paraspinal muscle retraction, partial or extensive laminectomy, and dural sac retraction to approach the herniated disc fragment. Therefore, considerable musculoskeletal or neural injuries may occur during the surgical approach. However, the transforaminal endoscopic approach provides rapid access to the herniated disc while bypassing the normal bony structures and paraspinal soft tissues. ${ }^{18-20}$

\section{EVIDENCE}

Among the various endoscopic spine surgery techniques, only the TELD technique has been proven by randomized controlled trials (RCTs) ${ }^{21-27}$ and systematic reviews with meta-analyses. ${ }^{28-31}$ Mayer and Brock $^{23}$ first performed an RCT comparing the clinical outcomes of TELD and open lumbar microdiscectomy. They concluded that TELD might be an excellent alternative to open surgery for patients with contained LDH. Hermantin et $\mathrm{al}^{21}$ found less postoperative disability and narcotic use with equal patient satisfaction in the TELD group in their high-quality RCT. Ruetten et $\mathrm{al}^{24,25}$ performed an RCT comparing the results of the full-endoscopic transforaminal discectomy to those of open discectomy and found that the results of the endoscopic procedure are equal to those of microdiscectomy with minimal tissue trauma. Gibson et $\mathrm{al}^{27}$ compared functional outcomes and perioperative data between TELD and microdiscectomy groups. They revealed that the operating results were similar, with a greater revision rate and more rapid recovery after TELD.

Recently published meta-analyses and systematic reviews commonly report that the TELD technique is equal to or superior to the standard open discectomy in terms of the minimal invasiveness and clinical effect of soft LDH. ${ }^{29-36}$ However, there may still be some criticism due to low-quality RCTs with a high risk of bias and limited surgical indications..$^{27,34-36}$ We also believe that more independent, high-quality RCTs with sufficient samples sizes reporting on multiple clinical outcomes and cost-effectiveness in the long term are needed.

\section{Surgical Technique: The Basics}

The surgical technique of TELD is composed of two processes: (1) percutaneous transforaminal approach under fluoroscopic guidance and (2) selective removal 
of herniated disc fragments under the endoscopic visual field.

The procedure is conducted based on the standard TELD technique under local anesthesia. ${ }^{10,18,37}$ Patients are positioned prone on a radiolucent operating table and kept under conscious sedation to check for adverse events. The skin entry is determined according to the procedure's purpose. It is also dictated by the patient's body size, foraminal dimensions, and the desired landing point on the disc surface. Preoperative magnetic resonance imaging (MRI) and computed tomography $(\mathrm{CT})$ images should be investigated to determine the skin entry point, a surgical tract, and the target landing point. Furthermore, intraoperative fluoroscopic imaging can guide the transforaminal endoscopic access according to the preoperative plan. The typical entry point is approximately 8 to $13 \mathrm{~cm}$ lateral to the midline. An 18-gauge needle is inserted under fluoroscopic guidance after local anesthetic infiltration. The needle tip is placed at the point between the medial and lateral pedicular line on the anteroposterior (AP) fluoroscopic view and the posterior vertebral line on the lateral fluoroscopic view or at the surface of the disc. A preemptive epidural block with $1 \%$ lidocaine before the intradiscal introduction of the needle is recommended to prevent approach-related or procedural pain. Then, discography is performed with a mixture of indigo carmine and contrast $(1 \mathrm{~mL}: 6 \mathrm{~mL})$. Pathological disc material is stained blue and can be easily distinguished from surrounding neural or soft tissues. This discography process is helpful for the precise removal of herniated disc fragments.

A guidewire then replaces the needle and a stab skin incision is made for obturator insertion. The cannulated obturator can slide over the guidewire and be inserted into the disc through the foraminal keyhole. During the obturator insertion step, considerable approachrelated pain may develop because of irritation to the exiting nerve root or any inflamed epidural tissues. A serial dilatation procedure using dilators of different sizes is applicable before obturator insertion to lessen the approaching pain. A bevel-ended working sheath is finally introduced over the obturator.

After the working sheath is safely placed to the disc, a rigid ellipsoidal endoscope, which has an eccentrically established working channel and 2 irrigation channels, is inserted. First, the surgeon must see the intradiscal space and indigocarmine-stained disc material through the endoscopic visual field. Initial subannular decompression can be performed using forceps and a radiofrequency coagulator, enabling the surgeon to confirm anatomical orientation. Anatomical layers or "strata," including the dural sac, adhered nerve root, surrounding epidural fat, congested annulus, and herniated nucleus, can be confirmed. It is critical to discriminate the herniated disc fragments and pathologic soft tissues from compressed neural tissues through an endoscopic view. The herniated disc is separated from the maternal disc and tightly adhered to the dural sac and nerve root.

Since a fibrotic annular fissure usually anchors the fragment, the annular anchorage should be released before removing the herniated disc. This releasing procedure can be conducted using a cutting rongeur, endoscopic punches, and sometimes a supplementary laser. Removing the adhered disc material without annular releasing step is challenging. The released and loosened main herniated fragment can be grasped with microforceps and other supplementary devices.

During selective discectomy, the surgeon must safely dissect tissues while keeping the neural tissues safe and decompressed. As these selective releasing and removing processes are performed, the angle of the endoscope and the visual field can be changed as required. The flexibility of the endoscopic angle and visualization is one of the advantages of the transforaminal endoscopic approach compared to the conventional open posterior approach. ${ }^{10,38}$ This levering technique enables the surgeon to widely examine the torn annulus and remove epidurally herniated disc fragments (Figure 2).

After removing the main mass of the herniated disc, the surgeon can identify the decompressed neural tissues. The end point of the procedure can be determined by checking for a strong pulsation of the dural sac and that the free mobilization of the nerve root is established. Some remnant disc materials that are tightly adhered to the neural tissue can be left if the end-point condition is confirmed. An excessive attempt to dissect the neural tissue may cause unexpected dural injury, which is the most critical complication of TELD. Finally, the endoscope is withdrawn, and a one-point subcutaneous suture is performed, followed by a sterile dressing. The patients can be discharged within 24 hours after checking for any postoperative complications.

\section{Surgical Technique: Advanced Keys to Success}

The standard TELD technique may be effective for the usual soft LDH presentation. However, there may be various complex presentations in actual practice, such as migrated, recurrent, or massive extruded LDH, as well as LDH with severe lateral recess syndrome. Therefore, besides the standard technique, we would 


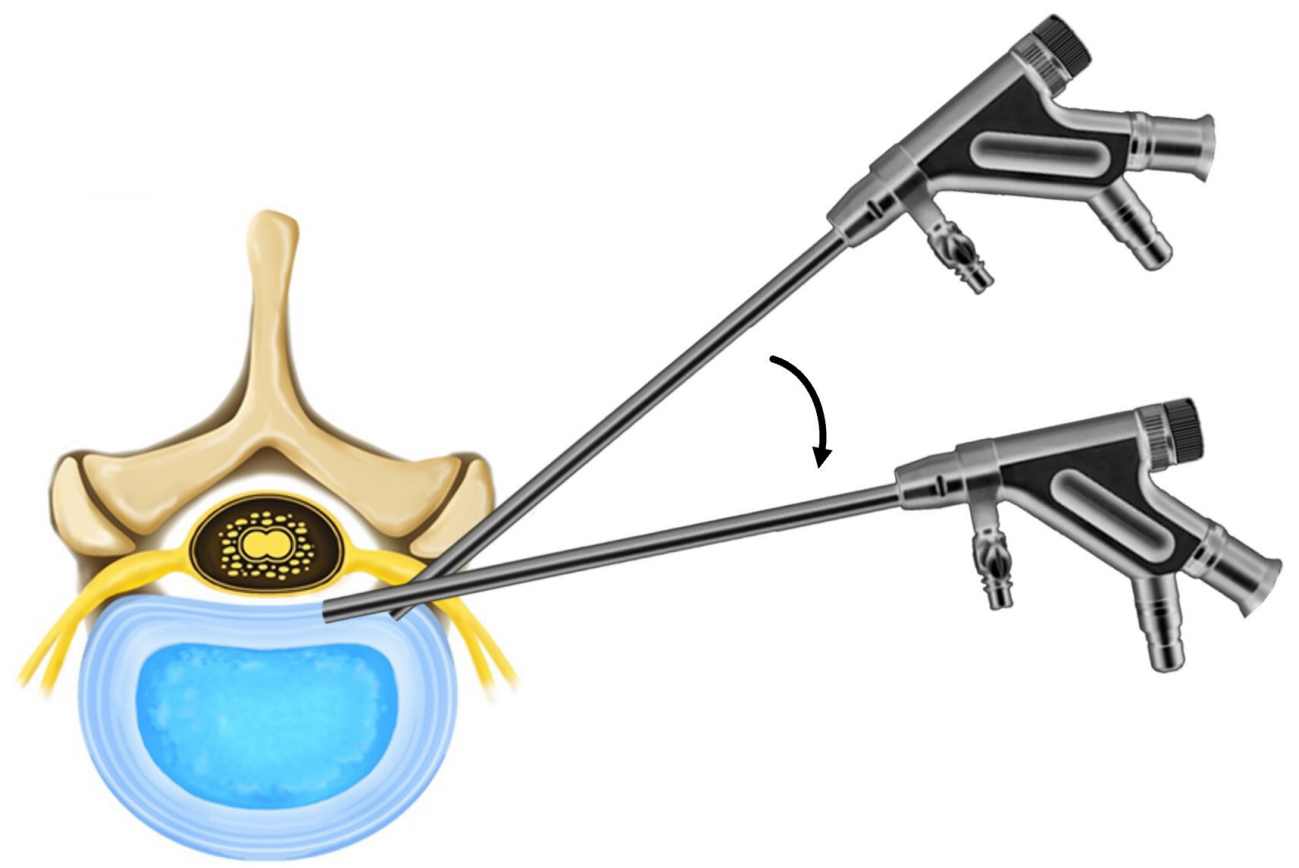

Figure 2. Levering technique. The angle of the endoscope and the visual field can be changed during the selective discectomy. This levering technique enables the surgeon to widely examine the torn annulus and remove epidurally herniated disc fragments.

like to emphasize the essential technical keys that can be applied to all types of LDH cases.

1. The initial approach should be conducted under lateral fluoroscopic projection rather than under the AP projection. With the lateral view, the surgeon can maintain the posterior vertebral line and prevent vascular or visceral injury during the transforaminal approach (Figure 3). Only after a safe landing on the disc surface can we use the AP view. The AP fluoroscopic view is usually not used while the endoscope approaches the foraminal area.
2. The needle tip should touch the lateral surface of the superior articular process. The needle can then slide into the foraminal window and intervertebral disc at the close point with the herniated disc. This needling technique prevents unnecessary irritation of the exiting nerve root. As a consequence, many beginner surgeons would not choose to carry on with TELD due to approach-related pain.

3. Holding the anatomical strata in the surgical field from an endoscopic view. After introducing the endoscope, the first step is to establish clear anatomical discrimination between neural and
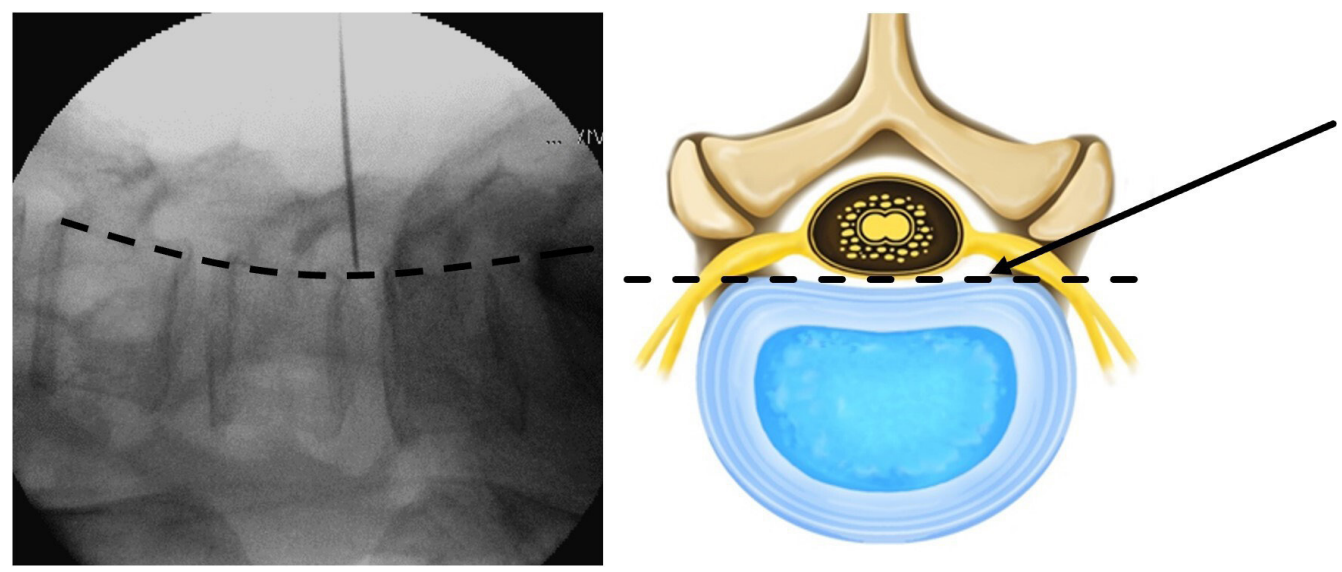

Figure 3. Lateral fluoroscopic view and schematic illustration of the transforaminal approach. The surgeon should not cross the posterior vertebral line (dashed line) until a disc landing is secured to prevent extraforaminal vascular or visceral injury. 
disc tissues. The dural sac and nerve root are usually covered by epidural fat and compressed by fibrotic disc tissues. Surgeons must recognize precisely what they can remove and what they should preserve.

4. The surgeon cannot remove the herniated disc before the annular anchorage is released. The pathologic disc is occasionally extruded into the epidural space through the annular fissure and anchored by the crack. After a careful and gradual opening of the fibrotic adhesion, the herniated fragment can be removed using fine forceps.

5. The precise end point is not the entire exposure of the neural tissues but a strong pulsation of the dural membrane. Leaving some adhesion tissues on the freely mobilized nerve is better than a dural tear, which is a critical complication. Too much is as bad as too little.

\section{PATIENT SELECTION}

Although endoscopic spine surgery techniques have a favorable clinical outcome with minimal invasiveness, one of the critical weak points of these procedures is the limitation of surgical candidates. The fundamental indications for TELD are (1) soft LDH as manifested on MRI and CT scans, (2) definitive lumbar radiculopathy compatible with the radiographic findings, and (3) failure of nonoperative treatment for at least 6 weeks. The contraindications for TELD are (1) severe central stenosis, (2) segmental instability, (3) painless weakness, (4) cauda equina syndrome, and (5) other pathologic conditions such as tumor or infection. However, there are a variety of different cases of LDH in actual practice. The situations vary, including patients with disc migration, recurrent disc herniation, massive disc herniation, neural entrapment with severe tissue adhesion, and soft disc herniation with concomitant stenosis. The success rate of endoscopic procedures may decrease in these complicated cases. Clinical outcomes may depend on the complexity of the cases. This "gray zone" is a dilemma of the minimally invasive surgical technique.

The evolution of endoscopic spine surgery has a history of expanding surgical indications. As surgical procedures have advanced, what can be done with endoscopes has widened. In the early era of endoscopic spine surgery, the main indication was contained LDH without disc migration or stenosis. As technology has advanced, complex cases such as highly migrated, far-lateral, or recurrent LDH can be treated with the modern concept of TELD. ${ }^{37,39-42}$ Surgical indications are constantly changing according to the level of the endoscopic surgical technology. Therefore, the best way to achieve a favorable outcome is to maintain the standard criteria of the present era.

\section{TECHNICAL TIPS TO PREVENT COMPLICATIONS}

Despite the excellent benefits of minimally invasive decompression and the effectiveness of the procedure, TELD has critical and inherent complications. Surgeons should keep these issues in mind to ensure clinical success.

\section{Exiting Nerve Root Irritation}

The first technical hurdle of the transforaminal approach is irritation of the exiting nerve root. The access needle, serial dilators, and working cannula should be introduced into the disc through the intervertebral foramen, preventing neural injury. Lack of care may damage the intact exiting nerve root, dorsal root ganglion, or possibly the furcal nerve..$^{10,43,44}$ If the patient is alert, neural irritation may cause severe approach-related pain and consequent failure of the procedure. If the patient was not aware of exiting nerve root irritation, it may cause postoperative dysesthesia or even profound neurological sequelae.

\section{Dural Tear}

The most critical complication of TELD may be a dural tear during tissue dissection and discectomy. ${ }^{45-47}$ If unrecognized, an intraoperative dural tear may cause disastrous sequelae. There are some unique features of dural tears in patients undergoing TELD that should be highlighted. First, it is challenging to detect dural tears because the procedure is usually performed under continuous saline irrigation. The surgical field is filled with fluid, and cerebrospinal fluid leakage and nerve root herniation cannot be recognized. Second, a dural tear is usually located on the ventral or ventrolateral side of the dural membrane. Therefore, a subsequent neurological deficit may occur in the form of motor weakness. Third, the risk of unrecognized dural tear may be higher than that of standard open microdiscectomy; therefore, postoperative flaring or neurologic deficits may be more critical. Finally, even if it can be detected during the procedure, intraoperative closure of the defect is challenging, and open revision surgery is usually immediately required. The most reliable way to prevent this critical complication is to maintain a precise anatomical layer during the entire process of dissection and 
decompression. Achievement of technical proficiency and overcoming the learning curve are mainly dependent on how to prevent dural tears.

\section{Infection (Epidural Abscess or Discitis)}

Surgical site infection after TELD is reported to be relatively rare compared to open surgery. However, like any other percutaneous intradiscal procedure, TELD carries the risk of postoperative spondylodiscitis. ${ }^{48,49}$ The clinical course of post-TELD spondylodiscitis may be more complicated than expected. First, the progression of infection is usually faster than that of open surgery. Infection signs and symptoms may occur several days after the procedure. The typical manifestations are unusual back pain, worsened radicular pain, fever, wound swelling, and possibly meningeal irritation signs. Concurrent clinical signs include the increase in infection markers such as C-reactive protein, erythrocyte sedimentation rate, neutrophil count, and procalcitonin levels. ${ }^{50,51}$ MRI at an early stage is not a reliable diagnostic tool for septic spondylodiscitis. ${ }^{52,53}$ After the early postoperative phase, signs of infection may appear on imaging studies such as MRI, CT, and simple radiography. A definite diagnosis can be made using percutaneous or open disc culture and biopsy. The first line of therapy is the use of appropriate antibiotics and bed rest for several weeks. If medical treatment fails, a decisive surgical incision and drainage may be considered.$^{54}$ To prevent this complication, continuous irrigation with preventive antibiotics during the entire procedure is essential. Surgical devices should be thoroughly disinfected due to the small size and complex structures of some components. Disposable instruments, such as radiofrequency or other supplementary devices, are recommended.

\section{Early Recurrence/Incomplete Decompression}

Although there is a lack of evidence, some critics may insist that the postoperative recurrence rate is higher than that of open microdiscectomy. Some patients may experience transient recurrent pain after a pain-free period. This transient flare-up usually improves 4 to 6 weeks after the procedure. However, some patients who complain of persistent radicular pain may need a second-look endoscopic procedure or open surgery. There are several explanations for the early symptom recurrence. First, endoscopic discectomy and decompression may be incomplete because of the presence of hidden disc fragments. The herniated piece usually adheres to the dural sac or nerve root and inflammatory tissue is present. Intradiscal or epidural tissue may be missed and remain around the neural tissues, even when the dural pulsation improves. In that case, the patient's symptoms only partially improve, and the radicular pain could relapse soon. Second, the amount of disc removed may not be sufficient to decompress the neural tissues. There may be loose disc fragments in the central nucleus that were not detected in the endoscopic visual field. The postoperative increase in disc pressure may cause herniation of the central core. Finally, there is little buffering space for the increased intradiscal pressure during the recovery period. TELD only comprises the removal of the herniated disc; laminectomy is not performed. The lack of posterior decompression is an inherent limitation of the TELD technique compared to open surgery. In open discectomy, there is a double decompression process: posterior laminectomy and ventral discectomy. Therefore, there may be more buffering space for postoperative increased discal pressure during the recovery period. Migrated or massive LDH with high canal compromise may lead to incomplete decompression. ${ }^{55,56}$ In contrast, a small, contained LDH may lead to postoperative recurrent disc herniation. To prevent incomplete decompression, precise knowledge of the endoscopic anatomy and recognition of the endpoint of decompression are mandatory. Complete removal of the entire fragment, including the base and tip of the herniated disc, is also essential for reducing recurrent disc herniation.

\section{Hematoma}

There may be two types of vascular insult associated with the TELD technique: retroperitoneal and epidural hematoma. Retroperitoneal hematoma is a unique vascular complication of the percutaneous transforaminal approach. ${ }^{57-59}$ Mechanical insult to the radicular lumbar artery or its branches may cause a significant hematoma in the open retroperitoneal space or psoas muscle. An emergency vascular intervention or open surgical evacuation may be required if this event occurs depending on the amount of hematoma or the patient's status. The transforaminal landing should be posterior to the posterior vertebral line before introduction into the disc to prevent vascular injury. In addition, the surgeon should be careful during foraminal or extraforaminal exploration near the radicular lumbar artery. Unlike in open surgery, postoperative epidural hematoma is relatively rare when performing TELD. If any, epidural hematomas are self-limiting or subclinical in most cases. However, significant epidural hematoma may occur if the endoscopic procedure includes a bone resection 
process or extensive epidural exploration. In such cases, insertion of an epidural drain may be necessary depending on the decompression technique.

\section{LEARNING CURVE}

\section{Cutoff Point}

The primary goal of the learning curve study is to determine the cutoff point or asymptote, indicating that technical proficiency has been achieved. The cutoff point can be defined as the number of cases in which the learning curve has plateaued and can differentiate the learning status between the training (early) and trained (late) stages of beginner surgeons. After such a number of cases, the operative time and patient outcomes can be significantly improved. ${ }^{60}$ Morgenstern et $\mathrm{al}^{61}$ revealed that a cutoff point of 72 cases is required to achieve good or excellent TELD outcomes in $90 \%$ of surgeries. According to a recent systematic review, the mean cutoff was $24.70 \pm 18.99$ cases (range 10-72 cases). ${ }^{60}$ However, the authors believe that achieving these values may not necessarily mean attaining a perfect surgical technique or ideal surgical outcomes. Instead, the learning curve may be ongoing even after the first cutoff point, because any minimally invasive or endoscopic spine technique is continuously being developed to allow for a higher level of surgical effectiveness.

\section{How to Speed Up the Learning Curve}

There are several ways to shorten the learning curve and becoming an expert faster. ${ }^{60}$ First, taking a systematic training class for the modern concept of TELD is one of the best ways to familiarize with the procedure. Wang et $\mathrm{al}^{62}$ demonstrated that a proper training course could reduce the learning period and improve clinical outcomes. The systematic training program includes conceptual lessons with audiovisual materials, hands-on workshops on dummy models or virtual reality programs, cadaver workshops, and participation in actual surgery as an assistant. Lack of sufficient experience in the systematic training course is the main reason for the failure of endoscopic surgery.

Second, proper patient selection is another critical factor for successful learning. Most endoscopic spine procedures have limitations in terms of surgical indications. If a beginner surgeon operates on a complex case, the results can be unfavorable, and the learning curve will be steeper. Therefore, a beginner surgeon should maintain stricter surgical indications until proficiency is achieved and the cutoff point is reached.
Regarding the level of discectomy, the L4-L5 level may be easier than the L5-S1 level or upper lumbar disc level in terms of accessibility and operative time. ${ }^{63}$

Finally, a supplementary navigation technique can ensure a precise approach is taken and facilitate the learning process. Fan et $\mathrm{al}^{64}$ revealed that introducing a preoperative location method reduced the operative time and access errors. This technique can also minimize radiation exposure by reducing fluoroscopy time during the transforaminal approach.

\section{REFERENCES}

1. Silvers HR. Microsurgical versus standard lumbar discectomy. Neurosurgery. 1988;22(5):837-841. doi:10.1227/00006123198805000-00005.

2. Kahanovitz N, Viola K, Muculloch J. Limited surgical discectomy and microdiscectomy. Spine. 1989;14(1):79-81. doi:10.1097/00007632-198901000-00016.

3. Caspar W, Campbell B, Barbier DD, Kretschmmer R, Gotfried Y. The Caspar microsurgical discectomy and comparison with a conventional standard lumbar disc procedure. Neurosurgery. 1991;28(1):78-86. doi:10.1097/00006123-199101000-00013.

4. Papavero L, Caspar W. The lumbar microdiscectomy. Acta Orthop Scand. 2009;64(sup251):34-37. doi:10.3109/17453679309160112.

5. Porchet F, Bartanusz V, Kleinstueck FS, et al. Microdiscectomy compared with standard discectomy: an old problem revisited with new outcome measures within the framework of a spine surgical registry. Eur Spine J. 2009;18 Suppl 3:360-366. doi:10.1007/ s00586-009-0917-9.

6. Calikoglu C, Cakir M. Open discectomy vs. microdiscectomy: results from 519 patients operated for lumbar disc herniation. Eurasian J Med. 2018;50(3):178-181. doi:10.5152/eurasianjmed.2018.18016.

7. Kambin P, Sampson S. Posterolateral percutaneous suctionexcision of herniated lumbar intervertebral discs. Clin Orthop Relat Res. 1986;207():37. doi:10.1097/00003086-198606000-00008.

8. Hijikata S. Percutaneous nucleotomy. A new concept technique and 12 years' experience. Clin Orthop. 1989;238:9-23.

9. Kambin P, Zhou L, Schaffer JL. Arthroscopic microdiscectomy and selective fragmentectomy. Clin Orthop Relat Res. 1998;347:150. doi:10.1097/00003086-199802000-00018.

10. Yeung AT, Tsou PM. Posterolateral endoscopic excision for lumbar disc herniation: surgical technique, outcome, and complications in 307 consecutive cases. Spine. 2002;27(7):722-731. doi:10.1097/00007632-200204010-00009.

11. Krugluger J, Knahr K. Minimally invasive disc surgery: a review. Int Orthop. 2001;24(6):303-306. doi:10.1007/ s002640000187.

12. Chang X, Chen B, Li H, Han X, Zhou Y, Li C. The safety and efficacy of minimally invasive discectomy: a metaanalysis of prospective randomised controlled trials. Int Orthop. 2014;38(6):1225-1234. doi:10.1007/s00264-014-2331-0.

13. Mayer HM, Brock M. Percutaneous endoscopic lumbar discectomy (PELD). Neurosurg Rev. 1993;16(2):115-120. doi:10.1007/BF00258242.

14. Ruetten S, Komp M, Godolias G. An extreme lateral access for the surgery of lumbar disc herniations inside the 
spinal canal using the full-endoscopic uniportal transforaminal approach-technique and prospective results of 463 patients. Spine. 2005;30(22):2570-2578. doi:10.1097/01.brs.0000186327.21435. cc.

15. Birkenmaier C, Komp M, Leu HF, Wegener B, Ruetten S. The current state of endoscopic disc surgery: review of controlled studies comparing full-endoscopic procedures for disc herniations to standard procedures. Pain Physician. 2013;16(4):335-344.

16. Ahn Y. Endoscopic spine discectomy: indications and outcomes. Int Orthop. 2019;43(4):909-916. doi:10.1007/s00264-01804283-w.

17. Hofstetter CP, Ahn Y, Choi G, et al. AOSpine consensus paper on nomenclature for working-channel endoscopic spinal procedures. Global Spine J. 2020;10(2 Suppl):111S-121S. doi:10.1177/2192568219887364.

18. Ahn Y. Transforaminal percutaneous endoscopic lumbar discectomy: technical tips to prevent complications. Expert Rev Med Devices. 2012;9(4):361-366. doi:10.1586/erd.12.23.

19. Wang K, Hong X, Zhou B-Y, et al. Evaluation of transforaminal endoscopic lumbar discectomy in the treatment of lumbar disc herniation. Int Orthop. 2015;39(8):1599-1604. doi:10.1007/ s00264-015-2747-1.

20. Ahn Y, Lee SG, Son S, Keum HJ. Transforaminal endoscopic lumbar discectomy versus open lumbar microdiscectomy: a comparative cohort study with a 5-year follow-Up. Pain Physician. 2019;22(3):295-304.

21. Hermantin FU, Peters T, Quartararo L, Kambin P. A prospective, randomized study comparing the results of open discectomy with those of video-assisted arthroscopic microdiscectomy. $J$ Bone Joint Surg Am. 1999;81(7):958-965. doi:10.2106/00004623199907000-00008.

22. Hoogland T, Schubert M, Miklitz B, Ramirez A. Transforaminal posterolateral endoscopic discectomy with or without the combination of a low-dose chymopapain: a prospective randomized study in 280 consecutive cases. Spine. 2006;31(24):E890-E897. doi:10.1097/01.brs.0000245955.22358.3a.

23. Mayer HM, Brock M. Percutaneous endoscopic discectomy: surgical technique and preliminary results compared to microsurgical discectomy. $J$ Neurosurg. 1993;78(2):216-225. doi:10.3171/jns.1993.78.2.0216.

24. Ruetten S, Komp M, Merk H, Godolias G. Full-endoscopic interlaminar and transforaminal lumbar discectomy versus conventional microsurgical technique. Spine. 2008;33(9):931-939. doi:10.1097/BRS.0b013e31816c8af7.

25. Ruetten S, Komp M, Merk H, Godolias G. Recurrent lumbar disc herniation after conventional discectomy: a prospective, randomized study comparing full-endoscopic interlaminar and transforaminal versus microsurgical revision. J Spinal Disord Tech. 2009;22(2):122-129. doi:10.1097/ BSD.0b013e318175ddb4.

26. Meyer G, DA Rocha ID, Cristante AF, et al. Percutaneous endoscopic lumbar discectomy versus microdiscectomy for the treatment of lumbar disc herniation: pain, disability, and complication rate-a randomized clinical trial. Int J Spine Surg. 2020;14(1):72-78. doi:10.14444/7010.

27. Gibson JNA, Subramanian AS, Scott CEH. A randomised controlled trial of transforaminal endoscopic discectomy vs microdiscectomy. Eur Spine J. 2017;26(3):847-856. doi:10.1007/s00586016-4885-6.

28. Nellensteijn J, Ostelo R, Bartels R, Peul W, van Royen B, van Tulder M. Transforaminal endoscopic surgery for symptomatic lumbar disc herniations: a systematic review of the literature. Eur Spine J. 2010;19(2):181-204. doi:10.1007/s00586-009-1155-x.

29. Cong L, Zhu Y, Tu G. A meta-analysis of endoscopic discectomy versus open discectomy for symptomatic lumbar disk herniation. Eur Spine J. 2016;25(1):134-143. doi:10.1007/s00586015-3776-6.

30. Li XC, Zhong CF, Deng GB, Liang RW, Huang CM. Fullendoscopic procedures versus traditional discectomy surgery for discectomy: a systematic review and meta-analysis of current global clinical trials. Pain Physician. 2016;19(3):103-118.

31. Ruan W, Feng F, Liu Z, Xie J, Cai L, Ping A. Comparison of percutaneous endoscopic lumbar discectomy versus open lumbar microdiscectomy for lumbar disc herniation: A meta-analysis. Int $J$ Surg. 2016;31:86-92. doi:10.1016/j.ijsu.2016.05.061.

32. Ding W, Yin J, Yan T, Nong L, Xu N. Meta-analysis of percutaneous transforaminal endoscopic discectomy vs. fenestration discectomy in the treatment of lumbar disc herniation. Orthopade. 2018;47(7):574-584. doi:10.1007/s00132-018-35285.

33. Zhang B, Liu S, Liu J, et al. Transforaminal endoscopic discectomy versus conventional microdiscectomy for lumbar discherniation: a systematic review and meta-analysis. J Orthop Surg Res. 2018;13(1):169. doi:10.1186/s13018-018-0868-0.

34. Barber SM, Nakhla J, Konakondla S, et al. Outcomes of endoscopic discectomy compared with open microdiscectomy and tubular microdiscectomy for lumbar disc herniations: a metaanalysis. J Neurosurg Spine. 2019;31(6):802-815. doi:10.3171/201 9.6.SPINE19532.

35. Gadjradj PS, Harhangi BS, Amelink J, et al. Percutaneous transforaminal endoscopic discectomy versus open microdiscectomy for lumbar disc herniation: a systematic review and meta-analysis. Spine. 2021;46(8):538-549. doi:10.1097/BRS.0000000000003843.

36. Li W-. S, Yan Q, Cong L. Comparison of endoscopic discectomy versus non-endoscopic discectomy for symptomatic lumbar sisc herniation: a systematic review and meta-analysis. Global Spine J. 2021;1:219256822110206. doi:10.1177/21925682211020696.

37. Ahn Y, Lee SH, Park WM, Lee HY, Shin SW, Kang HY. Percutaneous endoscopic lumbar discectomy for recurrent disc herniation: surgical technique, outcome, and prognostic factors of 43 consecutive cases. Spine. 2004;29(16):E326-E332. doi:10.1097/01. BRS.0000134591.32462.98.

38. Ahn Y, Lee SH, Lee JH, Kim JU, Liu WC. Transforaminal percutaneous endoscopic lumbar discectomy for upper lumbar disc herniation: clinical outcome, prognostic factors, and technical consideration. Acta Neurochir. 2009;151(3):199-206. doi:10.1007/ s00701-009-0204-x.

39. Yue JJ, Long W. Full endoscopic spinal surgery techniques: advancements, indications, and outcomes. Int J Spine Surg. 2015;9:17. doi:10.14444/2017.

40. Ahn Y, Jang IT, Kim WK. Transforaminal percutaneous endoscopic lumbar discectomy for very high-grade migrated disc herniation. Clin Neurol Neurosurg. 2016;147:11-17. doi:10.1016/j. clineuro.2016.05.016.

41. Zheng C, Wu F, Cai L. Transforaminal percutaneous endoscopic discectomy in the treatment of far-lateral lumbar disc herniations in children. Int Orthop. 2016;40(6):1099-1102. doi:10.1007/ s00264-016-3155-X.

42. Wang Y, Yan Y, Yang J, et al. Outcomes of percutaneous endoscopic trans-articular discectomy for huge central or paracentral lumbar disc herniation. Int Orthop. 2019;43(4):939-945. doi:10.1007/s00264-018-4210-6. 
43. Cho JY, Lee SH, Lee HY. Prevention of development of postoperative dysesthesia in transforaminal percutaneous endoscopic lumbar discectomy for intracanalicular lumbar disc herniation: floating retraction technique. Minim Invasive Neurosurg. 2011;54(5-6):214-218. doi:10.1055/s-0031-1287774.

44. Choi I, Ahn JO, So WS, Lee SJ, Choi IJ, Kim H. Exiting root injury in transforaminal endoscopic discectomy: preoperative image considerations for safety. Eur Spine J. 2013;22(11):2481-2487. doi:10.1007/s00586-013-2849-7.

45. Ahn Y, Lee HY, Lee SH, Lee JH. Dural tears in percutaneous endoscopic lumbar discectomy. Eur Spine J. 2011;20(1):58-64. doi:10.1007/s00586-010-1493-8.

46. Oertel JM, Burkhardt BW. Full endoscopic treatment of dural tears in lumbar spine surgery. Eur Spine J. 2017;26(10):2496-2503. doi:10.1007/s00586-017-5105-8.

47. Müller SJ, Burkhardt BW, Oertel JM. Management of dural tears in endoscopic lumbar spinal surgery: a review of the literature. World Neurosurg. 2018;119:494-499. doi:10.1016/j. wneu.2018.05.251.

48. Choi KB, Lee CD, Lee SH. Pyogenic spondylodiscitis after percutaneous endoscopic lumbar discectomy. J Korean Neurosurg Soc. 2010;48(5):455-460. doi:10.3340/jkns.2010.48.5.455.

49. Ahn Y, Lee SH. Postoperative spondylodiscitis following transforaminal percutaneous endoscopic lumbar discectomy: clinical characteristics and preventive strategies. $\mathrm{Br}$ J Neurosurg. 2012;26(4):482-486. doi:10.3109/02688697.2011.650739.

50. Schulitz KP, Assheuer J. Discitis after procedures on the intervertebral disc. Spine. 1994;19(Suppl):1172-1177. doi:10.1097/00007632-199405001-00016.

51. Meyer B, Schaller K, Rohde V, Hassler W. The C-reactive protein for detection of early infections after lumbar microdiscectomy. Acta neurochir. 1995;136(3-4):145-150. doi:10.1007/ BF01410617.

52. Grane P, Josephsson A, Seferlis A, Tullberg T. Septic and aseptic post-operative discitis in the lumbar spine--evaluation by MR imaging. Acta Radiol. 1998;39(2):108-115. doi:10.1080/02841859809172162.

53. Kylänpää-Bäck ML, Suominen RA, Salo SA, Soiva M, Korkala OL, Mokka RE. Postoperative discitis: outcome and late magnetic resonance image evaluation of ten patients. Ann Chir Gynaecol. 1999;88(1):61-64.

54. Shin JH, Ha KY, Kim KW, Lee JS, Joo MW. Surgical treatment for delayed pyogenic spondylitis after percutaneous vertebroplasty and kyphoplasty. [Report of 4 cases]. J Neurosurg Spine. 2008;9(3):265-272. doi:10.3171/SPI/2008/9/9/265.

55. Lee SH, Kang BU, Ahn Y, et al. Operative failure of percutaneous endoscopic lumbar discectomy: a radiologic analysis of 55 cases. Spine. 2006;31(10):E285-E290.

56. Lee S, Kim S-K, Lee S-H, et al. Percutaneous endoscopic lumbar discectomy for migrated disc herniation: classification of disc migration and surgical approaches. Eur Spine J. 2007;16(3):431-437. doi:10.1007/s00586-006-0219-4.

57. Kim HS, Ju CI, Kim SW, Kim JG. Huge psoas muscle hematoma due to lumbar segmental vessel injury following percutaneous endoscopic lumbar discectomy. J Korean Neurosurg Soc. 2009;45(3):192-195. doi:10.3340/jkns.2009.45.3.192.

58. Ahn Y, Kim JU, Lee BH, et al. Postoperative retroperitoneal hematoma following transforaminal percutaneous endoscopic lumbar discectomy. J Neurosurg Spine. 2009;10(6):595-602. doi:10 .3171/2009.2.SPINE08227.

59. Gioffrè G, Impusino A, Tacconi L. Retroperitoneal hematoma after minimally invasive lumbar discectomy: is the percutaneous endoscopic approach really safe. J Neurosurg Sci. 2019;63(2):231-233. doi:10.23736/S0390-5616.17.04156-X.

60. Ahn Y, Lee S, Son S, Kim H, Kim JE. Learning curve for transforaminal percutaneous endoscopic lumbar discectomy: a systematic review. World Neurosurg. 2020;143:471-479. doi:10.1016/j. wneu.2020.08.044.

61. Morgenstern R, Morgenstern C, Yeung AT. The learning curve in foraminal endoscopic discectomy: experience needed to achieve a 90\% success rate. SAS J. 2007;1(3):100-107. doi:10.1016/ SASJ-2007-0005-RR.

62. Wang H, Huang B, Li C, et al. Learning curve for percutaneous endoscopic lumbar discectomy depending on the surgeon's training level of minimally invasive spine surgery. Clin Neurol Neurosurg. 2013;115(10):1987-1991. doi:10.1016/j. clineuro.2013.06.008.

63. Wu X-. B, Fan G-. X, Gu X, et al. Learning curves of percutaneous endoscopic lumbar discectomy in transforaminal approach at the L4/5 and L5/S1 levels: a comparative study. J Zhejiang Univ Sci B. 2016;17(7):553-560. doi:10.1631/jzus.B1600002.

64. Fan G, Gu X, Liu Y, et al. Lower learning difficulty and fluoroscopy reduction of transforaminal percutaneous endoscopic lumbar discectomy with an accurate preoperative location method. Pain Physician. 2016;19(8):E1123-E1134.

Funding: The author(s) received no financial support for the research, authorship, and/or publication of this article.

Declaration of Conflicting Interests: The authors report no conflicts of interest or financial disclosures related to this article.

Corresponding Author: Yong Ahn, Department of Neurosurgery, Gil Medical Center, Gachon University College of Medicine, Incheon, South Korea; ns-ay@hanmail.net

Published 27 December 2021

This manuscript is generously published free of charge by ISASS, the International Society for the Advancement of Spine Surgery. Copyright (C) 2021 ISASS. To see more or order reprints or permissions, see http://ijssurgery.com. 